\title{
Experimental study on the interfacial behavior of normal and lightweight concrete
}

\author{
Shih Wei Cho (Main and Corresponding Author) \\ China University of Science and Technology, Department of Architecture \\ No.245, Academia Rd. Sec. 3, Nangang Dist., Taipei City 11581 (Taiwan) R.O.C. \\ swcho@cc.cust.edu.tw
}

\begin{abstract}
The interface between aggregate and mortar or paste is a weak phase. This has a serious effect on the properties of concretes. Because of the high porosity of lightweight aggregate, the interface of lightweight concrete is different from that of normal weight concrete. In this study, the effect of interfacial interactions between lightweight aggregate and mortar on the mechanical and chloride ion transport properties of concretes was investigated. The test variables were the volume fraction of the lightweight aggregate and the water-cement (W/C) ratio. The elastic modulus, the electrical charge passed from the rapid chloride penetration test (RCPT), and chloride ion penetration depth were determined. In addition, scanning electron microscopy (SEM) and energy-dispersive X-ray spectroscopy (EDX) were used to observe the microstructures of the interfaces. SEM observation of the lightweight concrete revealed that the interface bonding between mortar and aggregate is considerably firmer than that of normal weight concrete. However, test results indicate that the ability of the lightweight concrete to resist chloride ion intrusion is worse than that of normal weight concrete. Comparison with theoretical models reveals that a negative factor affects the chloride ion transmission in lightweight concrete. As the volume fraction of lightweight aggregate increased, this negative influence is also increased. Chloride ions were detected both in the mortar and the lightweight aggregate in the EDX test. This indicates that chloride ions passed through the lightweight aggregate during the RCPT and can thus influence chloride ion transmission throughout lightweight concrete.
\end{abstract}

Keywords: lightweight concrete, coarse aggregate, interfacial behavior, chloride ion, durability

Manuscript Code: 1297

Date of Acceptance/Reception: 17.10.2019/15.01.2019

DOI: $10.7764 / R D L C .18 .3 .476$

Introduction

In recent years, because the increased cost of mining natural aggregate and emphasis placed on recycling resources has led to lightweight aggregate consisting of clay, dirt, or fly ash being applied in concrete. In reinforced concrete structures, concrete accounts for $70 \%$ of the total weight. From the perspective of seismic resistance, concrete with lightweight aggregate has the advantage of low intrinsic weight. In addition, lightweight aggregate are usually inflated materials, and are thus highly effective for isolating noise and heat. Due to these advantages, lightweight concrete is regarded as an essential material in modern constructions (Owens, 1999; Weil et al., 2006; Hiete et al., 2011).

In addition to their different unit weights, natural aggregate and lightweight aggregate also differ in void ratio and surface roughness (Winslow et al., 1994; Bogas et al., 2014; Real et al., 2015). The transmission route of chloride ions has been thoroughly studied and simulated for normal weight concrete. Generally, it is assumed that chloride ions travel through the routes created by capillary voids and the interface transition area between aggregate and mortar. The range and the linkage of the interface transition area are the major factors that affect the transmission behavior of chloride ions in normal weight concrete (Choi et al., 2017; Liu et al., 2015; Wu et al., 2016). However, for lightweight concrete, linked voids may exist in the lightweight aggregate. Though high temperature sintering techniques can vitrify the surfaces of the lightweight aggregate and minimize the dimensions of the open holes, whether the surface denseness after vitrification can cut off the transmission of chloride ions to the same degree as in normal weight aggregate has not been investigated. Irrespective of what type of manufacturing process is applied, the surface roughness of the lightweight aggregate is usually higher if no microcracks occur; this roughness can form a stronger mechanical interlocking with mortar than the natural aggregate. On the basis of bending and compression test results and analysis of the composite material model, Husem (2003) found that the linkage strength between lightweight aggregate and mortar is 2.5 times stronger than that between natural aggregate and mortar. The aforementioned studies indicate that, with the same water-cement $(\mathrm{W} / \mathrm{C})$ ratio and volume, the strength of normal weight concrete is usually higher than that of lightweight concrete. The cause of this is generally interpreted as being because the voids in lightweight aggregate decrease the elastic modulus. Therefore, if the strength of cement mortar is higher than that of the lightweight aggregate (approximately 30 to $35 \mathrm{MPa}$ is mentioned in the references) the failure of the concrete is controlled by the strength of the aggregate. Chen et al. (1999) applied the dividing strength theorem proposed by Weigler and Karl in the context of test results to explain the relationship between the strengths of the lightweight aggregate and whole concrete. From the perspective of microstructure, Lo \& Gui (2004) observed that the propagation of microcracks that exist in the aggregate-mortar interface area is the main factor affecting mechanical properties. The interfaces between aggregate and mortar are quite different. Because this difference may 
affect chloride ion transmission and the mechanical properties, a series of experiments are carried out to determine these effects in this study.

\section{Materials and methods}

The lightweight aggregate used in this research were sintered material. The maximum size of the lightweight aggregate was $10 \mathrm{~mm}$, with a fineness modulus of 5.75 , and density of $1250 \mathrm{~kg} / \mathrm{m}^{3}$ (under saturated surface dry (SSD) conditions). Analysis of the interface characteristics of the lightweight concrete was performed by comparing the properties of whole normal weight and lightweight concrete with the same $\mathrm{W} / \mathrm{C}$ ratio and aggregate volume. Crushed stone was employed as the normal weight coarse aggregate in this research. The maximum size of the normal weight coarse aggregate was $10 \mathrm{~mm}$, with a fineness modulus of 5.83 , and density of $2750 \mathrm{~kg} / \mathrm{m}^{3}$ (under SSD conditions). All specimens contained $10 \%$ fine aggregate by total mortar volume. The fine aggregate used in this research was river sand. The fineness modulus of the fine aggregate was 2.91 , with a density of $2720 \mathrm{~kg} / \mathrm{m}^{3}$ (under SSD conditions). Light aggregate and normal aggregate were added with ratios ranging from $0 \%$ to $40 \%$ of the total volume. The mixture designs of the specimens and the mechanical properties of the test results are listed in Tables 1 and 2.

\begin{tabular}{|c|c|c|c|c|c|c|c|}
\hline $\mathrm{W} / \mathrm{C}$ & $\begin{array}{l}\text { Volume } \\
\text { of coarse } \\
\text { aggregate } \\
(\%)\end{array}$ & $\begin{array}{l}\text { Cement } \\
\left(\mathrm{kg} / \mathrm{m}^{3}\right)\end{array}$ & $\begin{array}{c}\text { Water } \\
\left(\mathrm{kg} / \mathrm{m}^{3}\right)\end{array}$ & $\begin{array}{c}\text { Lightweight } \\
\text { aggregate } \\
\left(\mathrm{kg} / \mathrm{m}^{3}\right)\end{array}$ & $\begin{array}{c}\text { Fine } \\
\text { aggregate } \\
\left(\mathrm{kg} / \mathrm{m}^{3}\right)\end{array}$ & $\begin{array}{l}\text { Compression } \\
\text { strength } \\
(\mathrm{MPa})\end{array}$ & $\begin{array}{c}\text { Elastic } \\
\text { modulus } \\
(\mathrm{GPa})\end{array}$ \\
\hline \multirow[t]{5}{*}{0.3} & 0 & 1425 & 428 & 0 & 272 & 55.23 & 28.65 \\
\hline & 10 & 1279 & 384 & 125 & 245 & 50.75 & 22.34 \\
\hline & 20 & 1134 & 340 & 250 & 218 & 47.72 & 20.82 \\
\hline & 30 & 988 & 296 & 375 & 190 & 45.33 & 19.91 \\
\hline & 40 & 842 & 253 & 500 & 163 & 43.10 & 18.54 \\
\hline \multirow[t]{5}{*}{0.4} & 0 & 1227 & 491 & 0 & 272 & 39.55 & 22.45 \\
\hline & 10 & 1101 & 440 & 125 & 245 & 37.22 & 19.26 \\
\hline & 20 & 976 & 390 & 250 & 218 & 36.85 & 17.95 \\
\hline & 30 & 850 & 340 & 375 & 190 & 33.49 & 16.95 \\
\hline & 40 & 725 & 290 & 500 & 163 & 30.25 & 15.54 \\
\hline \multirow[t]{5}{*}{0.5} & 0 & 1077 & 538 & 0 & 272 & 28.76 & 20.15 \\
\hline & 10 & 966 & 483 & 125 & 245 & 27.55 & 17.56 \\
\hline & 20 & 856 & 428 & 250 & 218 & 25.84 & 15.77 \\
\hline & 30 & 746 & 373 & 375 & 190 & 22.68 & 13.95 \\
\hline & 40 & 636 & 318 & 500 & 163 & 20.75 & 12.31 \\
\hline
\end{tabular}

To evaluate the chloride ion transmission by a rapid chloride penetration test (RCPT), RCPT ASTM C1202 was applied. In this test, saturated cylinder specimens $(10 \mathrm{~cm}$ diameter and $5 \mathrm{~cm}$ height $)$ are placed in two acrylic chambers. A piece of a copper net with \#20 sieves is used in each chamber as an electrode. To avoid producing chloride gas during the test, the positive electrode chamber is filled with $0.3 \mathrm{~N} \mathrm{NaOH}$ solution and the negative electrode chamber is filled with $3 \% \mathrm{NaCl}$ solution. A $60 \mathrm{~V} \mathrm{DC}$ voltage is then applied to the two chambers. During a test period of 360 minutes a data logger automatically records the current passed through the specimens and the temperature of the solution every minute. With the relationship between the measured current and time, Equation (1) can be employed to calculate the total electric charge that is passed.

$Q=\int I_{t}(t) d t$

where $Q$ is the total charge passed and the unit is coulombs. $I_{t}$ is the current measured at time $t$ and the unit is amperes. The total charge passed is then utilized to evaluate the ability of concrete to resist the penetration of chloride ions. After the test, the specimens are split and the cleavage surfaces are sprayed with $0.01 \mathrm{~N} \mathrm{AgNO}_{3}$. By observing the color change, the chloride ion intrusion depth of the concrete is estimated. 
Table 2. Mixture design and mechanical properties of normal weight concretes. Source: Self-Elaboration.

\begin{tabular}{|c|c|c|c|c|c|c|c|}
\hline $\mathrm{W} / \mathrm{C}$ & $\begin{array}{l}\text { Volume } \\
\text { of coarse } \\
\text { aggregate } \\
(\%)\end{array}$ & $\begin{array}{l}\text { Cement } \\
\left(\mathrm{kg} / \mathrm{m}^{3}\right)\end{array}$ & $\begin{array}{c}\text { Water } \\
\left(\mathrm{kg} / \mathrm{m}^{3}\right)\end{array}$ & $\begin{array}{l}\text { Normal weight } \\
\text { aggregate } \\
\left(\mathrm{kg} / \mathrm{m}^{3}\right)\end{array}$ & $\begin{array}{c}\text { Fine } \\
\text { aggregate } \\
\left(\mathrm{kg} / \mathrm{m}^{3}\right)\end{array}$ & $\begin{array}{c}\text { Compression } \\
\text { strength } \\
(\mathrm{MPa})\end{array}$ & $\begin{array}{c}\text { Elastic } \\
\text { modulus } \\
(\mathrm{GPa})\end{array}$ \\
\hline \multirow[t]{5}{*}{0.3} & 0 & 1425 & 428 & 0 & 272 & 55.23 & 28.65 \\
\hline & 10 & 1279 & 384 & 275 & 245 & 56.03 & 27.99 \\
\hline & 20 & 1134 & 340 & 550 & 218 & 54.95 & 27.54 \\
\hline & 30 & 988 & 296 & 825 & 190 & 54.57 & 28.12 \\
\hline & 40 & 842 & 253 & 1100 & 163 & 53.29 & 28.09 \\
\hline \multirow[t]{5}{*}{0.4} & 0 & 1227 & 491 & 0 & 272 & 39.55 & 22.45 \\
\hline & 10 & 1101 & 440 & 275 & 245 & 39.15 & 20.96 \\
\hline & 20 & 976 & 390 & 550 & 218 & 38.12 & 20.14 \\
\hline & 30 & 850 & 340 & 825 & 190 & 37.58 & 19.31 \\
\hline & 40 & 725 & 290 & 1100 & 163 & 36.24 & 18.84 \\
\hline \multirow[t]{5}{*}{0.5} & 0 & 1077 & 538 & 0 & 272 & 28.76 & 20.15 \\
\hline & 10 & 966 & 483 & 275 & 245 & 27.28 & 19.55 \\
\hline & 20 & 856 & 428 & 550 & 218 & 26.87 & 18.46 \\
\hline & 30 & 746 & 373 & 825 & 190 & 24.91 & 17.54 \\
\hline & 40 & 636 & 318 & 1100 & 163 & 22.94 & 16.35 \\
\hline
\end{tabular}

\section{Results and discussion}

The compression test results of the cylinder specimens $(10 \mathrm{~cm}$ diameter and $20 \mathrm{~cm}$ height) after 91 days of curing are illustrated in Figure 1. The results indicate that with a W/C ratio of 0.3 , the compressive strength different is only 2.74 $\mathrm{MPa}$ of the normal weight aggregate concretes with different volume fraction. However, with $\mathrm{W} / \mathrm{C}$ ratios of 0.4 and 0.5 , the strength tends to decrease as the volume of the aggregate increases. For lightweight concrete, the strength of the concrete markedly decreases as the volume of the aggregate increases, irrespective of the W/C ratio. Taking the $\mathrm{W} / \mathrm{C}$ ratio of 0.4 as an example, adding $40 \%$ volume of normal weight aggregate reduces the strength of the concrete by approximately 3.31 MPa relative to that of concrete without added aggregate. However, for the concrete specimen with $40 \%$ volume of lightweight aggregate added, the strength is reduced by approximately $9.3 \mathrm{MPa}$. Figure 2 illustrates the elastic modulus values of the cylinder specimens $(10 \mathrm{~cm}$ diameter and $20 \mathrm{~cm}$ height) after 91 days of curing. Figure 1 shows that the inclinations are nearly the same as the compression strength. With a low W/C ratio of 0.3 the elastic modulus of the normal weight concrete is less affected by the aggregate. However, for lightweight concrete, the elastic modulus is reduced as the volume of aggregate increased. Although the amount of paste decreases as the volume of aggregate increases, and may affect the mechanical properties of the concrete. However it is found from the comparison of the test results that it is mainly affected by the properties of the aggregate itself. Many studies have the same results and conclusions (Lo \& Gui, 2004; Chen et al., 1999). Researchers such as Chen et al. (1999) also used theory to calculate the difference in the properties of lightweight aggregate and normal weight aggregate.

The RCPT results of the specimens after 91 days of curing are listed in Table 3. Each value in this table is the average of the test results of three specimens. The table indicates that for both normal weight concrete specimens and lightweight concrete specimens, the total charge passed decreased as the volume of aggregate increased. Based on ASTM C1202, a lower current demonstrates that resistance to the penetration of ions is better. However, regarding the penetration depth of chloride ions, normal weight concrete and lightweight concrete behave differently. For lightweight concrete, the chloride ion penetration depth is increased as the volume of the lightweight aggregate is increased. For normal weight concrete, this trend is reversed, and the effect is not obvious as the volume of aggregate is increased. 
Table 3. Experimental results of chloride ion transmission: Source: Self-Elaboration.

\begin{tabular}{|c|c|c|c|c|c|}
\hline \multirow[b]{2}{*}{$\mathrm{W} / \mathrm{C}$} & \multirow{2}{*}{$\begin{array}{c}\text { Volume of } \\
\text { aggregate } \\
\text { (\%) }\end{array}$} & \multicolumn{2}{|c|}{ Lightweight concrete } & \multicolumn{2}{|c|}{ Normal weight concrete } \\
\hline & & $\begin{array}{c}\text { Total charge } \\
\text { (coulomb) }\end{array}$ & $\begin{array}{l}\mathrm{Cl}^{-} \text {penetration depth } \\
(\mathrm{mm})\end{array}$ & $\begin{array}{c}\text { Total charge } \\
\text { (coulomb) }\end{array}$ & $\begin{array}{l}\mathrm{Cl}^{-} \text {penetration depth } \\
(\mathrm{mm})\end{array}$ \\
\hline \multirow[t]{5}{*}{0.30} & 0 & 4207 & 16.44 & 4207 & 16.44 \\
\hline & 10 & 3834 & 18.87 & 3530 & 6.36 \\
\hline & 20 & 3578 & 18.58 & 3065 & 5.59 \\
\hline & 30 & 3001 & 21.82 & 2494 & 5.39 \\
\hline & 40 & 2640 & 22.57 & 1996 & 4.60 \\
\hline \multirow[t]{5}{*}{0.45} & 0 & 5192 & 28.33 & 5192 & 28.33 \\
\hline & 10 & 4917 & 29.08 & 4443 & 17.16 \\
\hline & 20 & 4202 & 29.41 & 3845 & 17.06 \\
\hline & 30 & 3873 & 33.59 & 3131 & 15.80 \\
\hline & 40 & 3180 & 39.96 & 2660 & 14.76 \\
\hline \multirow[t]{5}{*}{0.55} & 0 & 15214 & 34.15 & 15214 & 34.15 \\
\hline & 10 & 13571 & 31.43 & 13088 & 33.17 \\
\hline & 20 & 12803 & $>50.00$ & 11672 & 32.89 \\
\hline & 30 & 11141 & $>50.00$ & 9494 & 32.52 \\
\hline & 40 & 9775 & $>50.00$ & 8501 & 32.02 \\
\hline
\end{tabular}

Figure 1. Relation between 91-day compression strengths and aggregate volumes: (a) normal weight concrete; (b) lightweight concrete. Source: Self-Elaboration

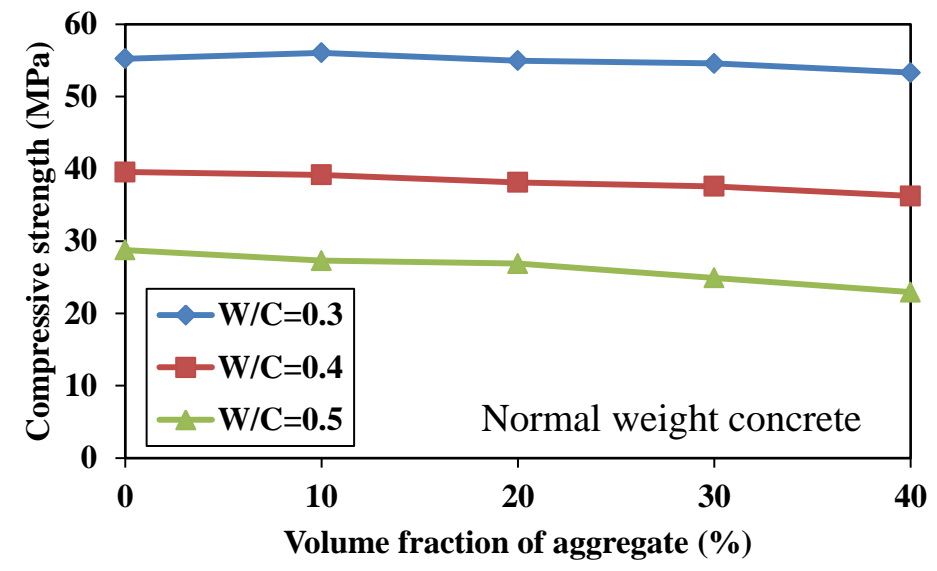

(a)

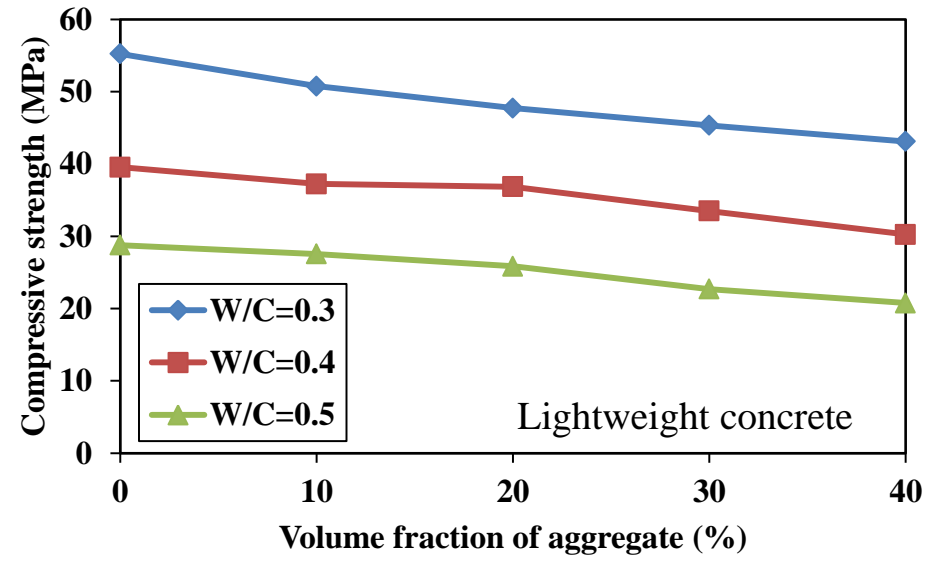

(b) 
Figure 2. Relation between the elastic modulus values of 91-day concrete and aggregate volumes: (a) normal weight concrete; (b) lightweight concrete. Source: Self-Elaboration

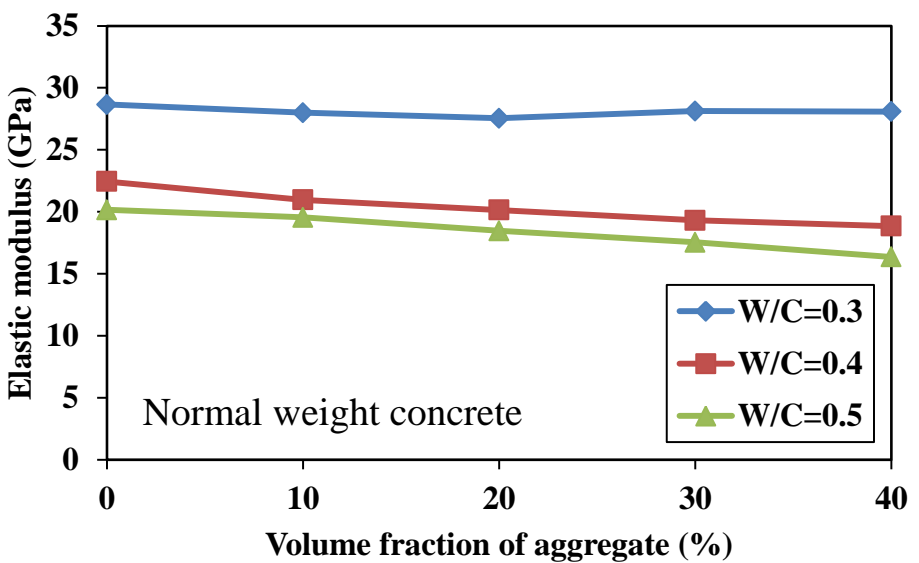

(a)

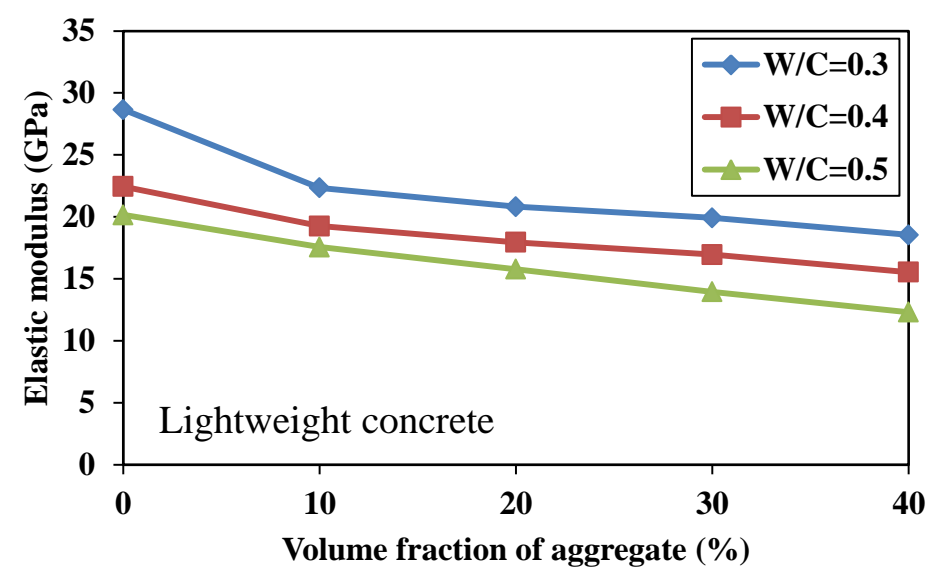

(b)

In 1999, Shah (2000) proposed four effects of aggregate that influence the diffusion rate in cement-based composite materials. These four factors are dilution, tortuosity, the interfacial transition zone, and percolation. The dilution effect can be caused by the high denseness and low permeability of aggregate prohibiting ions from transferring. Thus, the transmission routes are mainly through the cement mortar and the interface area between the mortar and aggregate. From the standpoint of resisting ion transfer, this effect is positive. The dilution and tortuosity effects both benefit from the low permeability of aggregate. However, unlike the dilution effect, the tortuosity effect causes ion detour along the edges of the aggregate when the transmission routes are blocked by the aggregate. Because the paths are tortuous instead of straight, the transmission distances are longer, and the speeds are hindered. This effect is also positive for resisting ion transfer. The interfacial transition zones are the discontinuous sparse areas between the mortar and aggregate. For cement-based composite materials, the interfacial transition zones can be considered to be areas with small cracks. When ions are blocked by aggregate, this transition zone provides paths for detouring. Thus, this is a negative effect for resisting ion transfer. The width and fineness of the interfacial transition zone are the main factors affecting transmission behavior. These two factors are related to the shapes of aggregate and the W/C ratio. The percolation effect is derived from the effect of the interfacial transition zone, and is therefore a negative effect. If the volume of an aggregate is too large, the distances between aggregate are shrunk. Therefore, the interfacial transition zones overlap, which provides chloride ions with paths through which to transfer rapidly.

The relations of the total charge passed that were observed in RCPT and the aggregate volume fractions are plotted in Figures $3(\mathrm{a}), 4(\mathrm{a})$ and $5(\mathrm{a})$, in which the $\mathrm{W} / \mathrm{C}$ ratios are $0.3,0.4$, and 0.5 , respectively. These figures indicate that for both aggregate, the total passed charges are decreased as the volume fractions are increased. The dilution and tortuosity effect are addressed in the following equations:

Dilution effect: $K_{c l}=K_{M}\left(1-V_{f}\right)$

Dilution effect and tortuosity effect: $K_{c l}=K_{M}\left(1-V_{f}\right)^{1.5}$ 
where $K_{c l}$ is the chloride ion transmission of concrete, $K_{M}$ is the chloride ion transmission of mortar, and $V_{f}$ is the volume fraction of coarse aggregate. The bold lines are plotted with Equation (2) and the dotted lines are plotted with Equation (3).
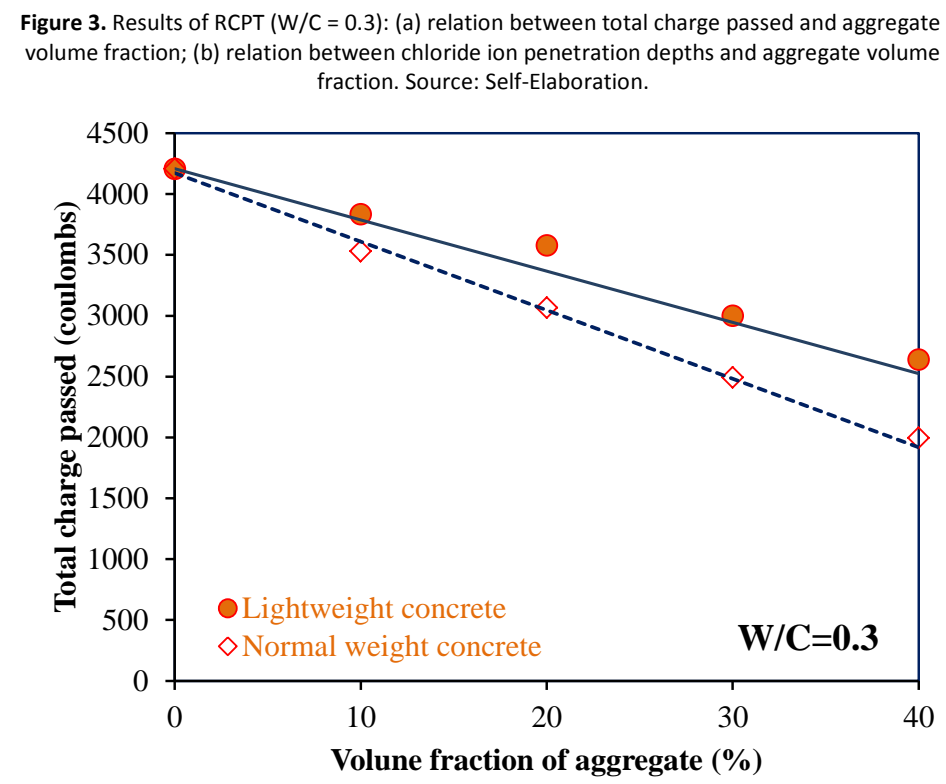

(a)

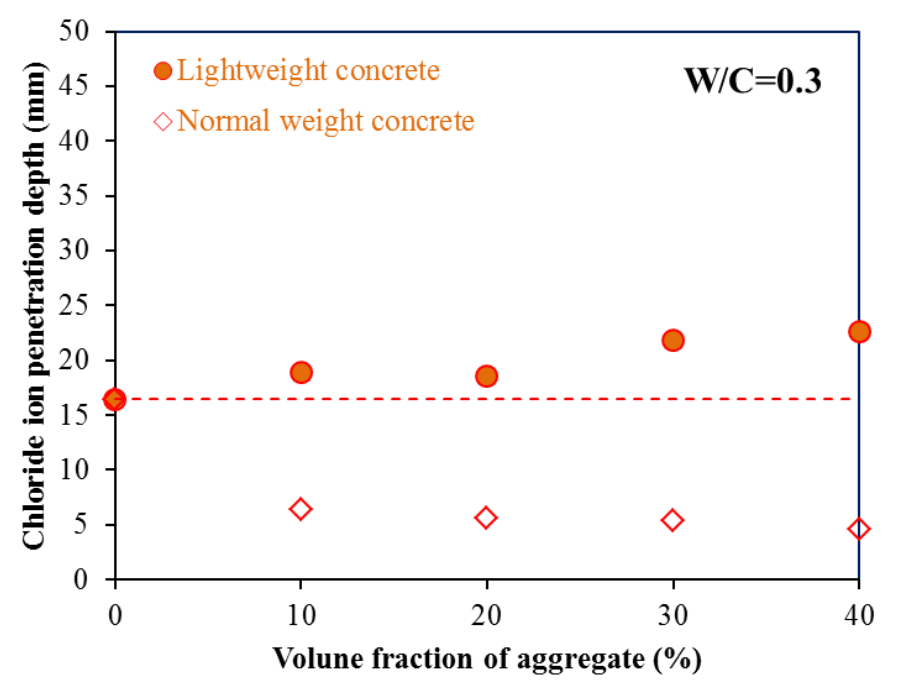

(b)

Figure 3 indicates that if the W/C ratio is 0.3 , the RCPT results of the lightweight concretes are close to those suggested by the dilution effect theory but higher than those of the equation for the dilution and tortuosity effects. The RCPT results of the normal weight concrete are close to those of the equation for the dilution and tortuosity effects. Generally, if the W/C ratio is smaller than 0.3 , the interface between the mortar and aggregate is not clear. Therefore, for the RCPT results of the normal weight concretes to be close to the dotted line is reasonable, considering the dilution effect and the tortuosity effect. However, for the lightweight concrete, there must be a negative effect leading to the increase of the total charge passed. With W/C ratios of 0.4 and 0.5 , the RCPT results of the lightweight concretes gradually diverge from those predicted by the dilution equation. For normal weight concrete, as the $\mathrm{W} / \mathrm{C}$ ratio is increased, the test results exceed those of the equation for the dilution and tortuosity theory, but become closer to the dilution equation. Because the fineness of the normal aggregate is far greater than that of mortar, the inclinations exhibited in Figures 4 and 5 can be interpreted as being caused by negative influence from the interfacial transition zones. For lightweight concrete, the test results all are larger than the dilution equation irrespective of the W/C ratio, suggesting that there is a negative effect larger than the interfacial transition zone effect. 
Figure 4. Results of RCPT (W/C $=0.4$ ): (a) relation between total charge passed and aggregate volume fraction; (b) relation between chloride ion penetration depths and aggregate volume fraction. Source: Self-Elaboration.

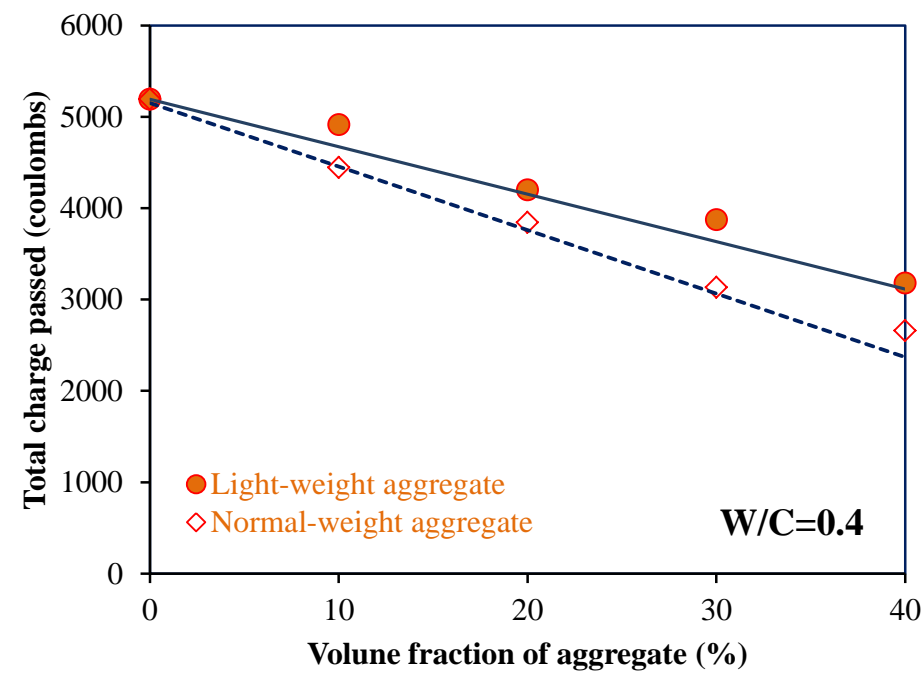

(a)

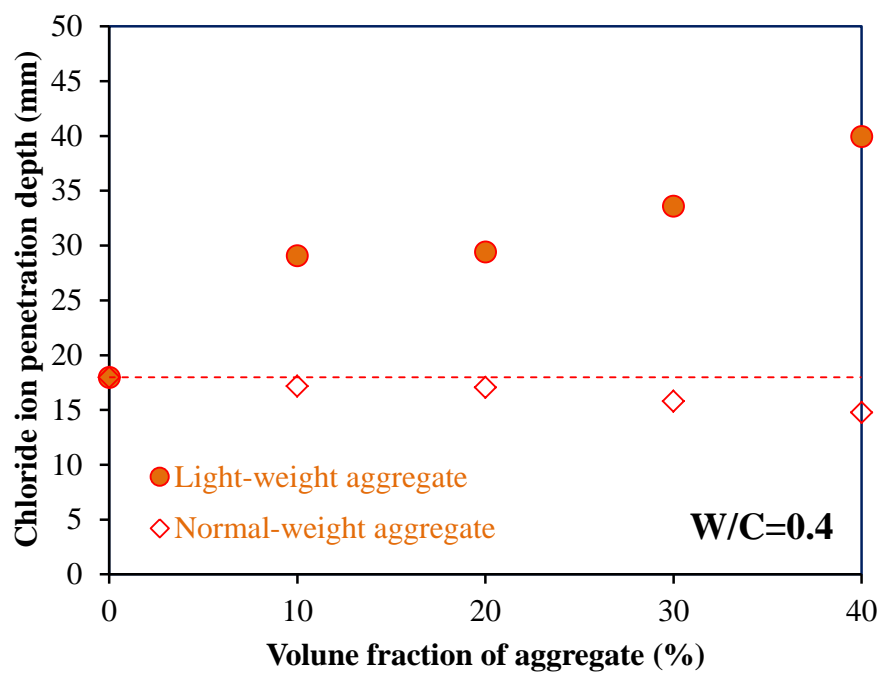

(b)

Figure 5. Results of RCPT (W/C $=0.5)$ : (a) relation between total charge passed and aggregate volume fraction; (b) relation between chloride ion penetration depths and aggregate volume fraction. Source: Self-Elaboration

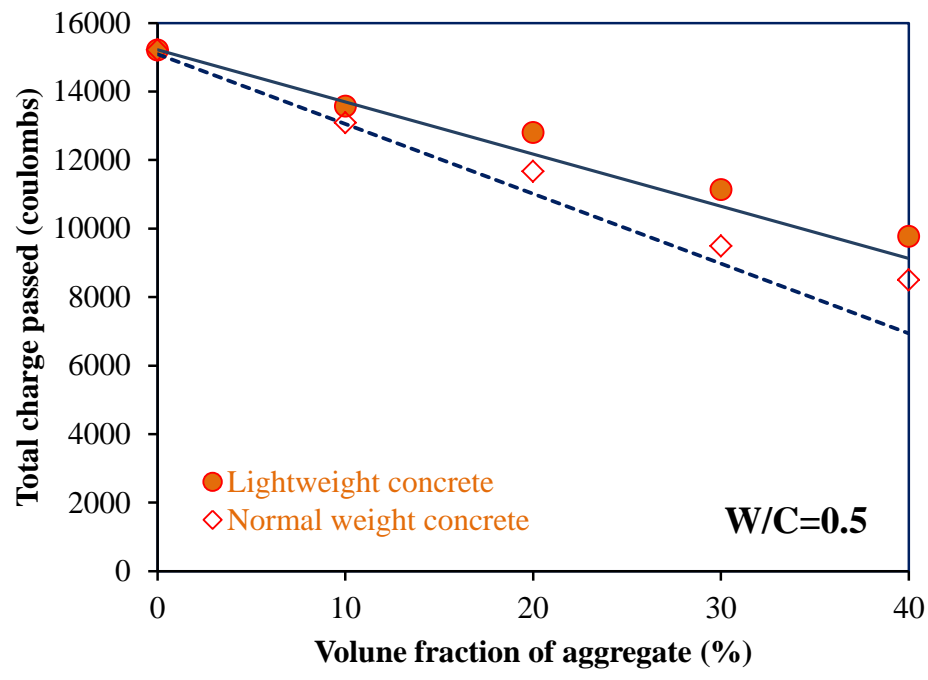

(a) 


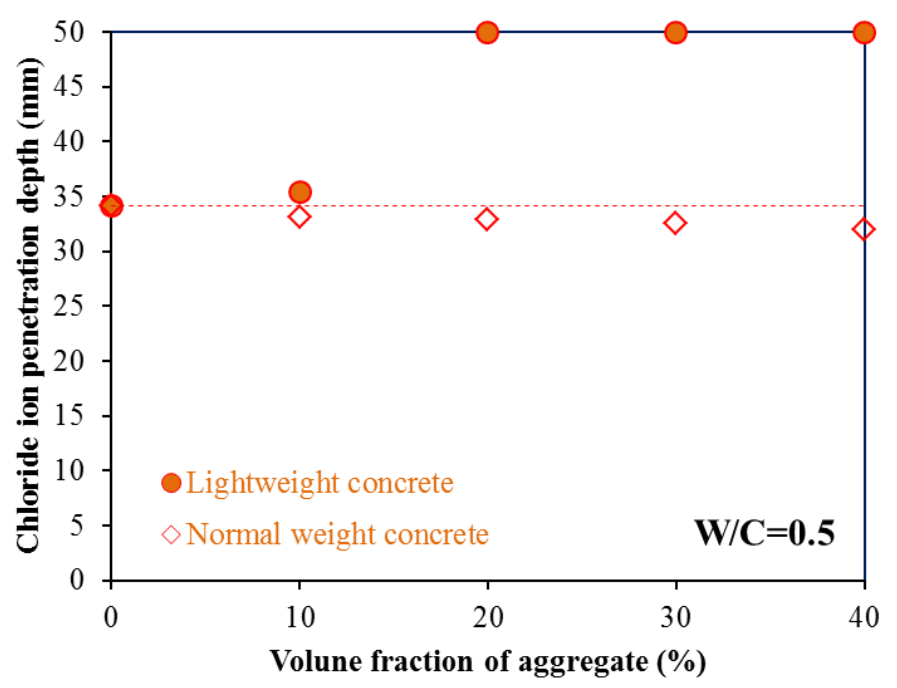

(b)

Regarding the intruding depth of chloride ions, for normal weight concrete, the depth is shorter as the volume fraction of aggregate increases, irrespective of the W/C ratio. This means that the normal weight aggregate have a positive influence on the dilution and tortuosity effects. However, for lightweight concrete, the opposite results are obtained. In other words, the ion resistance of the lightweight aggregate may affect all aspects of chloride ion transmission.

To observe the microstructures, normal weight aggregate, lightweight aggregate, and mortar with a $0.45 \mathrm{~W} / \mathrm{C}$ ratio were prepared for mercury intrusion porosimetry (MIP) tests. The results are shown in Figure 6 and indicate that the void ratios of lightweight aggregate and mortar are approximately the same. However, for normal aggregate, the ratio is markedly smaller. An SEM picture and the EDX analysis result for fresh lightweight aggregate are provided in Figure 7. The interior of the lightweight aggregate is filled with pore structures. In addition, no chloride ions are present.
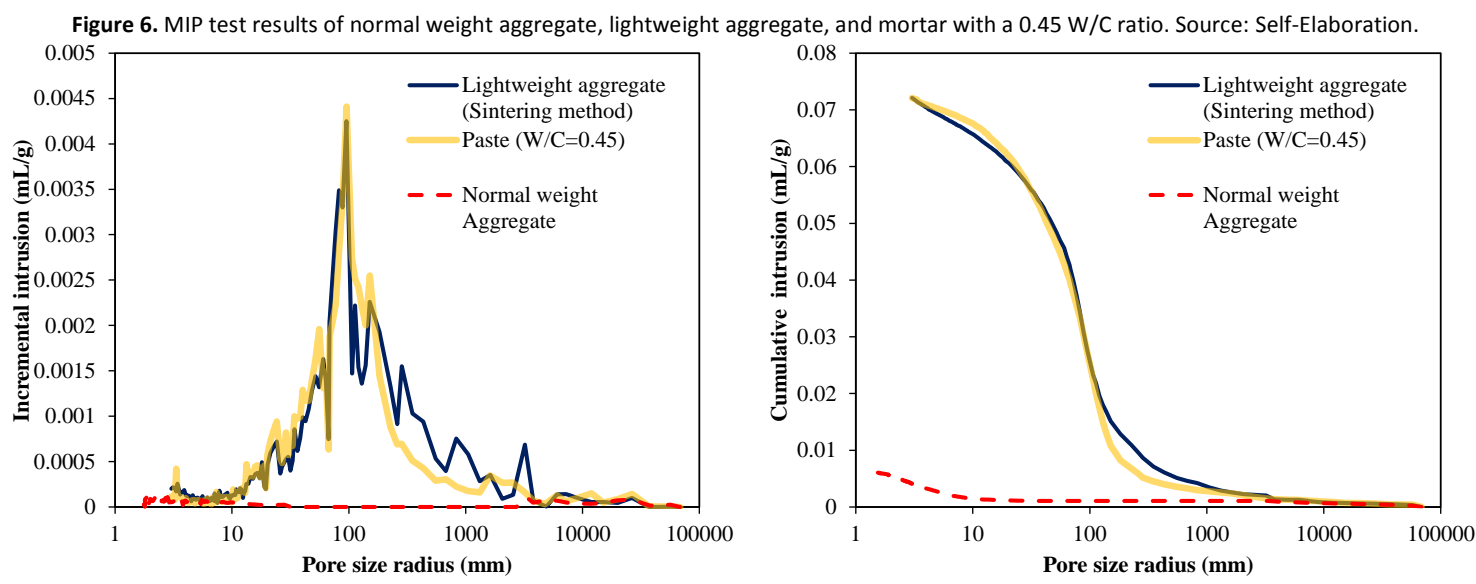

The SEM and EDX analysis results for lightweight concrete with a $0.3 \mathrm{~W} / \mathrm{C}$ ratio are shown in Figure 8 and indicate that the interface bonding between the mortar and aggregate is excellent. In addition, no chloride ions are present in the mortar or the aggregate. The SEM and EDX analysis results from after the RCPT are shown in Figure 9 and indicate the presence of chloride ions in the mortar and aggregate. This result indicates that chloride ions passed through lightweight aggregate during the RCPT. 
Figure 7. SEM and EDX analysis results of lightweight aggregate. Source: Self-Elaboration.

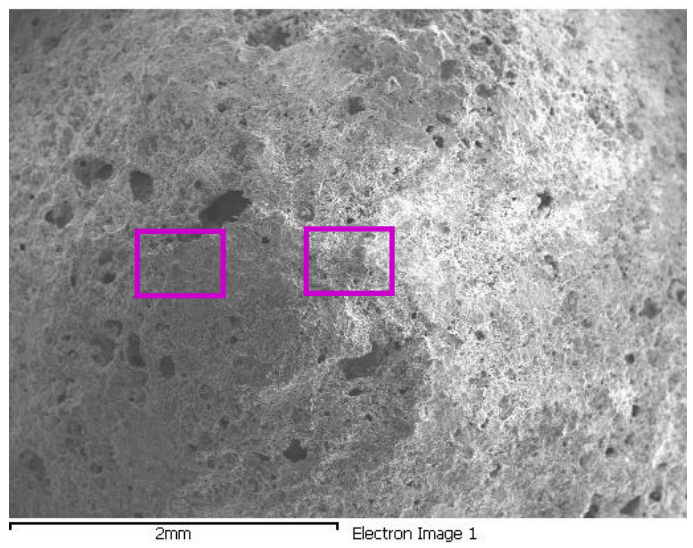

\begin{tabular}{c|cc}
\hline Element & Weight\% & Atomic\% \\
C K & 5.31 & 9.03 \\
O K & 48.10 & 61.41 \\
Mg K & 4.47 & 3.75 \\
Al K & 7.63 & 5.77 \\
Si K & 16.37 & 11.91 \\
K K & 2.79 & 1.46 \\
Ca K & 7.40 & 3.77 \\
Fe K & 7.92 & 2.90 \\
\hline
\end{tabular}

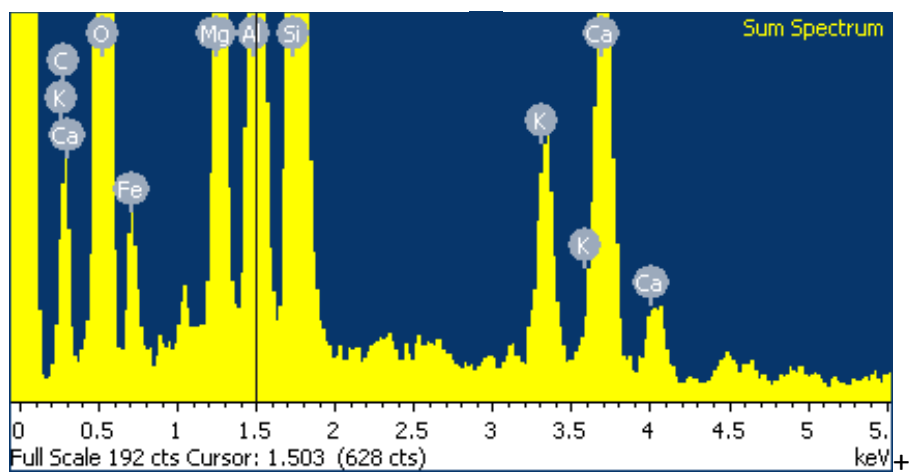

Figure 8. SEM and EDX analysis results of the lightweight concrete $(W / C=0.3)$ before rapid chloride penetration testing: (a) EDX spectra of mortar; (b) EDX spectra of lightweight aggregate. Source: Self-Elaboration

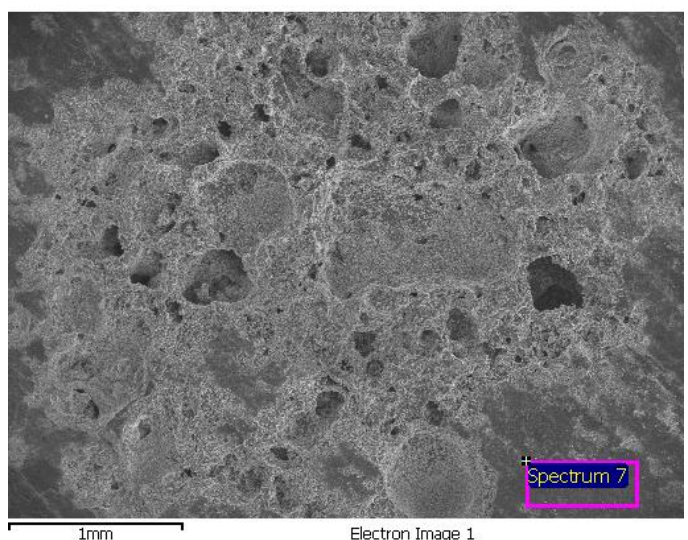

\begin{tabular}{c|cc}
\hline Element & Weight\% & Atomic\% \\
C K & 7.33 & 12.02 \\
O K & 54.99 & 67.69 \\
Al K & 1.87 & 1.36 \\
Si K & 6.32 & 4.43 \\
Ca K & 29.49 & 14.49 \\
\hline
\end{tabular}

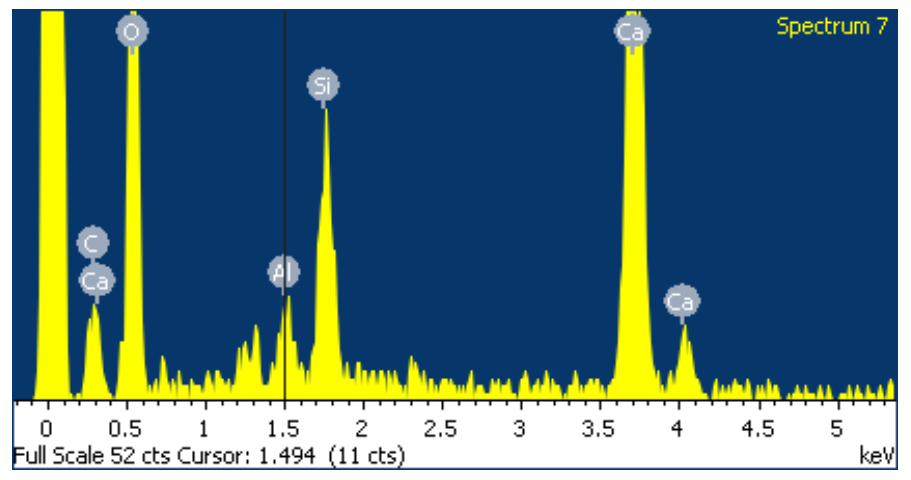

(a) 


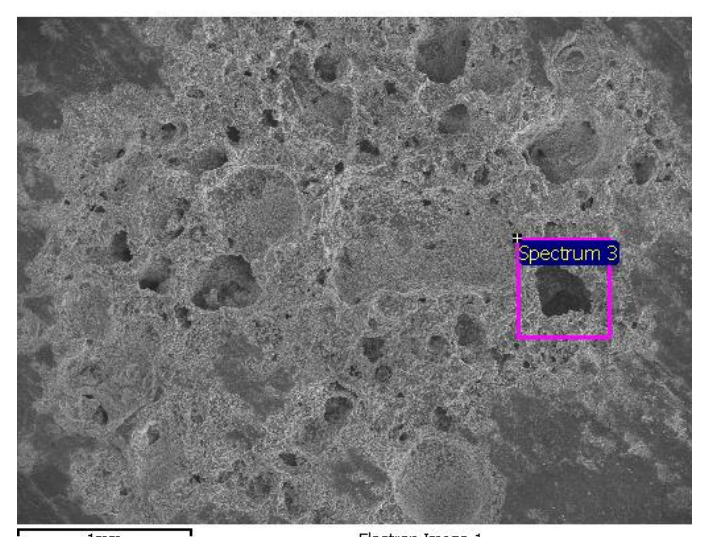

\begin{tabular}{c|cc}
\hline Element & Weight\% & Atomic\% \\
O K & 53.92 & 68.98 \\
Mg K & 4.30 & 3.62 \\
Al K & 8.81 & 6.68 \\
Si K & 17.77 & 12.95 \\
Ca K & 15.21 & 7.77 \\
\hline
\end{tabular}

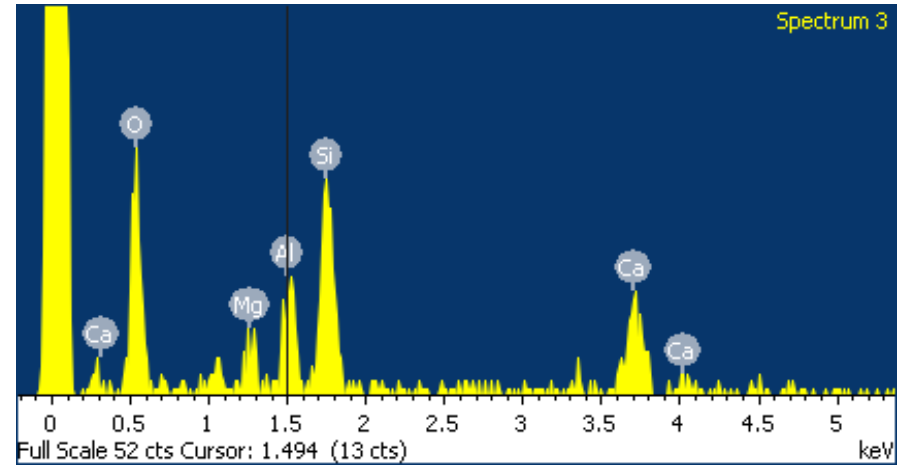

(b)

Figure 9. SEM and EDX analysis results of lightweight concrete $(W / C=0.3)$ after rapid chloride penetration testing: (a) EDX spectra of mortar; (b) EDX spectra of lightweight aggregate. Source: Self-Elaboration

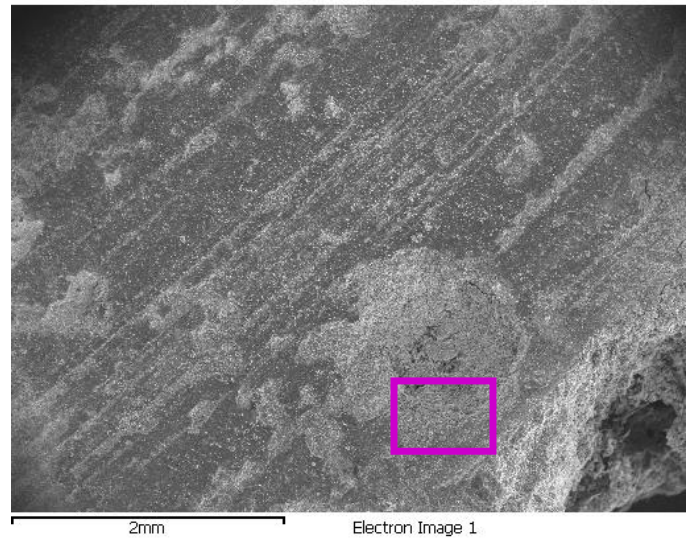

\begin{tabular}{c|cc}
\hline Element & Weight\% & Atomic\% \\
C K & 9.66 & 15.40 \\
O K & 55.45 & 66.32 \\
Si K & 7.82 & 5.33 \\
Cl K & 0.52 & 0.28 \\
Ca K & 26.55 & 12.68 \\
\hline
\end{tabular}

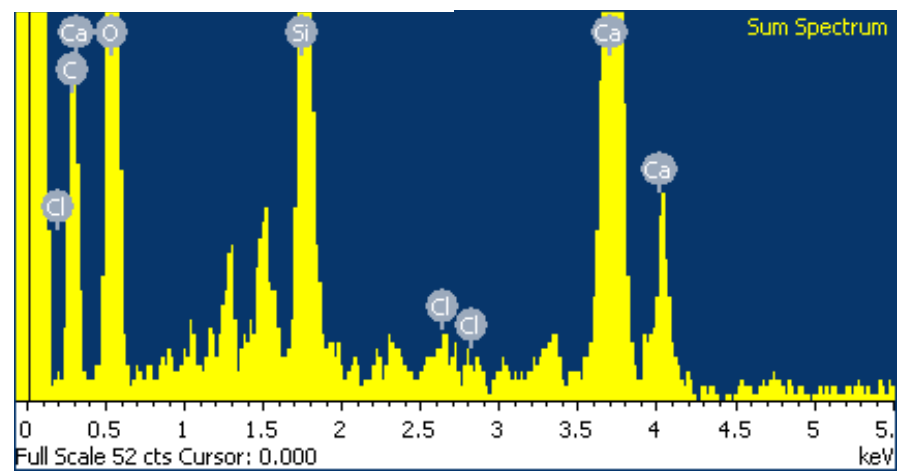

(a) 


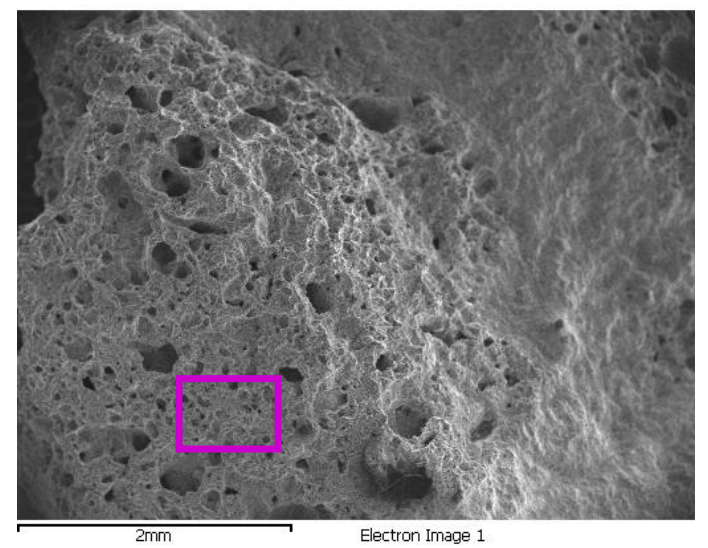

\begin{tabular}{c|cc}
\hline Element & Weight\% & Atomic\% \\
O K & 59.14 & 74.15 \\
Mg K & 2.42 & 1.99 \\
Al K & 6.05 & 4.50 \\
Si K & 14.38 & 10.27 \\
Cl K & 0.32 & 0.18 \\
K K & 4.03 & 2.07 \\
Ca K & 13.66 & 6.84 \\
\hline
\end{tabular}

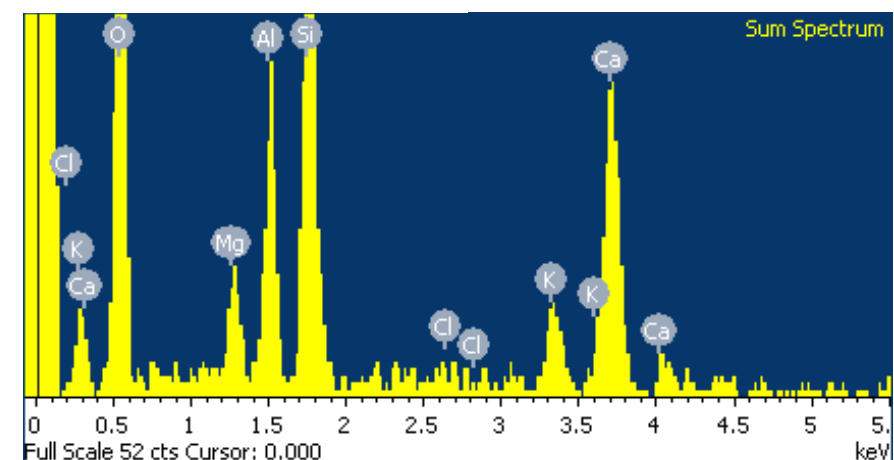

(b)

- Regarding mechanical properties, normal weight concrete with a low W/C ratio is less affected by aggregate. However, irrespective of the $\mathrm{W} / \mathrm{C}$ ratio, the strengths and elastic modulus values of lightweight concretes are decreased as the volume fraction of lightweight aggregate is increased. That is, the properties of lightweight aggregate may affect the mechanical properties of concretes.

- The RCPT results and penetration depths of chloride ions indicate that the ability of lightweight concrete to resist chloride ion intrusion is inferior to that of normal weight concrete.

- Compared with the theoretical models, the RCPT results of normal weight concrete are slightly higher than the results yielded by the equation for dilution and tortuosity effects. That is, an interfacial transition zone effect occurs. This effect is also enlarged as the $\mathrm{W} / \mathrm{C}$ ratio increases.

- The RCPT results of lightweight concrete are all higher than the values indicated by the dilution equation. This means that there is a negative factor which affects chloride ion transmission. As the volume fraction of lightweight aggregate is increased, this negative influence is also increased.

- SEM observation of lightweight concrete reveals that the interface bonding between mortar and lightweight aggregate is very firm.

- Following rapid chloride penetration testing of lightweight concrete, chloride ions can be found both in mortar and lightweight aggregate using EDX. This confirms that chloride ions passed through lightweight aggregate during the RCPT.

\section{Acknowledgments}

This study was financial supported by the Ministry of Science and Technology Scientific Research Projects, under the grants of NSC 94-2221-E-157-004 is gratefully appreciated. (Taipei, Taiwan, R.O.C.) 
Bogas, J. A., Gomes, M. G., \& Real, S. (2014). Capillary absorption of structural lightweight aggregate concrete. Materials and Structures, 48(9), $2869-2883$

Chen, H. J., Yen, T., Lia, T. P., \& Huang, Y. L. (1999). Determination of the dividing strength and its relation to the concrete strength in lightweight aggregate concrete. Cement and Concrete Composites, 21(1), 29-37.

Choi, Y. C., Park, B., Pang, G. S., Lee, K. M, \& Choi, S. C. (2017). Modelling of chloride diffusivity in concrete considering effect of aggregate. Construction and Building Materials, 136, 81-87.

Hiete, M., Stengel, J., Ludwig, J., \& Schultmann, F. (2011). Matching construction and demolition waste supply to recycling demand: A regional management chain model. Building research and information, 39(4), 333-351.

Husem, M. (2003). The effects of bond strengths between lightweight and ordinary aggregate-mortar, aggregate-cement paste on the mechanical properties of concrete, Materials Science and Engineering: A, 363(1-2), 152-158.

Liu, Q. F., Easterbrook, D., Yang, J., \& Li, L. Y. (2015). A three-phase, multi-component ionic transport model for simulation of chloride penetration in concrete. Engineering Structure, 86, 122-133.

Lo, T. Y., \& Cui, H. Z. (2004). Effect of porous lightweight aggregate on strength of concrete. Materials Letters, 58(6), 916-919.

Owens, P. L. (1999). Structure lightweight aggregate concrete-the future?. Concrete, 33(10), 45-47.

Real, S., Bogas, J. A., \& Pontes, J. (2015). Chloride migration in structural lightweight aggregate concrete produced with different binders. Construction and Building Materials, 98, 425-436.

Shah, S. P. (2000). High performance concrete: past, present and future, in high performance concrete- workability, strength and durability. Proceedings of an International Conference, Hong Kong, 3-29.

Weil, M., Jeske, U., \& Schebek, L. (2006). Closed-loop recycling of construction and demolition waste in Germany in view of stricter environmental threshold values. Waste Management \& Research, 24(3), 197-206.

Winslow, D. N., Cohen, M. D., Bentz, D. P., \& Garboczi, E. J. (1994). Percolation and pore structure in mortars and concrete. Cement and Concrete Research, 24(1), 25-37.

Wu, K., Shi, H., Xu, L., Ye, G., \& Schutter, G. D. (2016). Microstructural characterization of ITZ in blended cement concretes and its relation to transport properties. Cement and Concrete Research, 79, 243-256. 